\title{
Factors affecting the efficacy of radioiodine therapy in patients with Grave's disease
}

\author{
Magdalena Pogwizd, Agata Baldys-Waligorska, Dorota Pach, Monika Tomaszuk, \\ Monika Bereza-Buziak and Alicja Hubalewska-Dydejczyk
}

${ }^{1}$ Department of Endocrinology, Faculty of Medicine, Jagiellonian University Medical College, Krakow, Poland

Introduction

In the treatment of hyperthyroidism, the optimum activity of radioiodine is yet to be established. We analysed factors affecting the efficacy of 131-I radiotherapy in Graves' disease (GD) patients.

Materials and Methods

Table 1. General characteristics of the studied group ( $\mathrm{N}=362$ patients)

\begin{tabular}{|c|c|}
\hline Age years - median [IQR] & $53.0[25]$ \\
\hline Gender: females (\%) /males (\%) & $\begin{array}{c}293(80.9 \%) / 69 \\
(19.1 \%)\end{array}$ \\
\hline 1st treatment with $131-\mathrm{I}(\%)$ & $309(85.4 \%)$ \\
\hline Successive admonistration of 131-I (\%) & $53(14.6 \%)$ \\
\hline $\begin{array}{l}\text { Patients treated with first onset of } \\
\text { hyperthyroidism }\end{array}$ & $22(6.1 \%)$ \\
\hline $\begin{array}{l}\text { Patients treated at first recurrence of } \\
\text { hyperthyreodism }\end{array}$ & $174(48.1 \%)$ \\
\hline $\begin{array}{l}\text { Patients treated at successive } \\
\text { recurrence of hyperthyreodism }\end{array}$ & $165(45.8 \%)$ \\
\hline ATD before 131-I treatment & \\
\hline No (\%) & $53(14.6 \%)$ \\
\hline Yes(\%) & $309(85.4 \%)$ \\
\hline Graves orbitopathy & \\
\hline Absent (\%) & $334(92.3 \%)$ \\
\hline Present before 131-I treatment (\%) & $28(7.7 \%)$ \\
\hline
\end{tabular}

Table 2. Results of laboratory tests in studied group ( $\mathrm{N}=362$ patients)

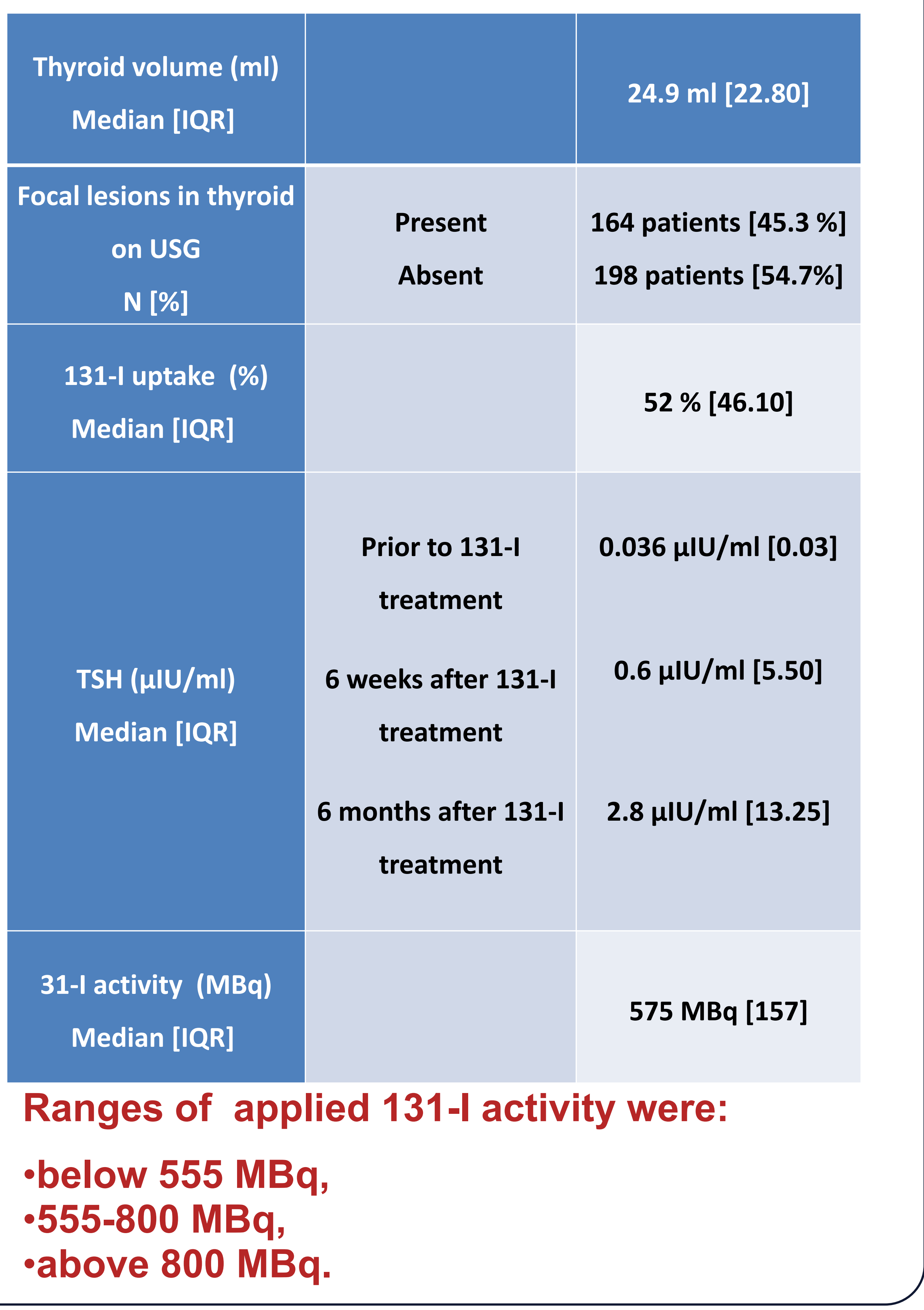

\section{Results}

The median thyroid volume was significantly larger in men $(30 \mathrm{ml}$ [18.95-52.75]) than in women (24 $\mathrm{ml}[16.1-37])(p=0.006)$. No significant differences in efficacy related to 131-I activity applied were stated six months post treatment.

Six months post $131-$ I treatment, in $72 \%$ of patients, euthyroidism or hypothyroidism was stated.

In the group of patients treated with 131-I activity less than $555 \mathrm{MBq}$ or in the range 555 $800 \mathrm{MBq}, 76 \%$ or $68.5 \%$ of patients were cured, respectively,

Presence of focal lesions did not affect the efficacy of 131-I treatment.

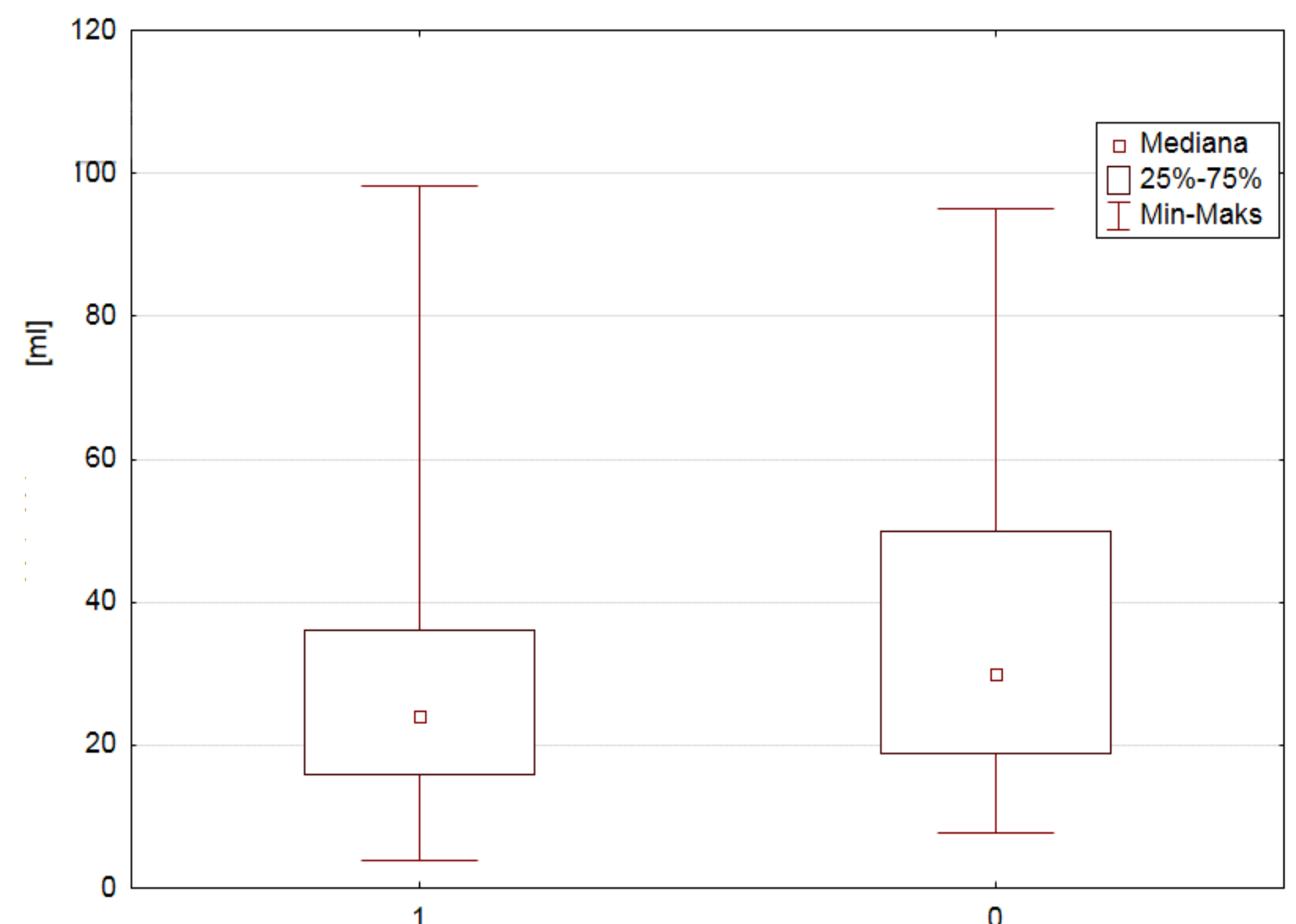

Figure 1. Thyroid volume in female (1)

or male $(0)$ patients treated with $131-1$

( $U$ Mann-Whitney test, $p=0.006$ ).

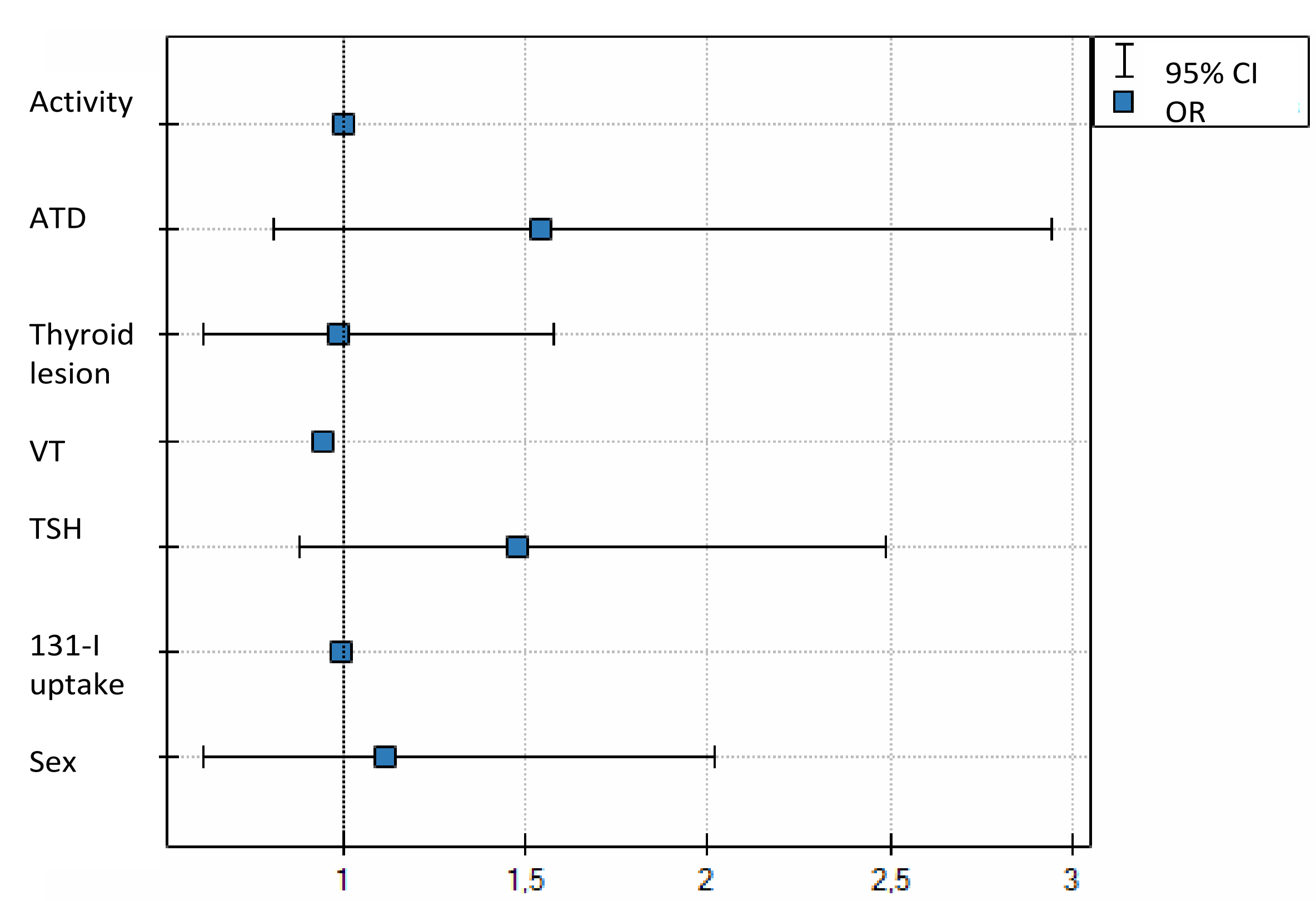

Figure 3. Factors affecting 131-I therapy efficacy - 6 weeks after treatment (logistic regression, $\mathrm{N}=356$ )

Only two factors were effective: thyroid volume: the smaller was
the thyroid volume, the more effective was the treatment $(0 R-0.95$ the
$0<0.001,95 \% \mathrm{Cl}=0.31-0.66)$, and the activity of radioiodine delivered ( $(\mathrm{R}-1.003, \mathrm{p}=0.004 ; 95 \% \mathrm{Cl}=1.001-1.005)$.

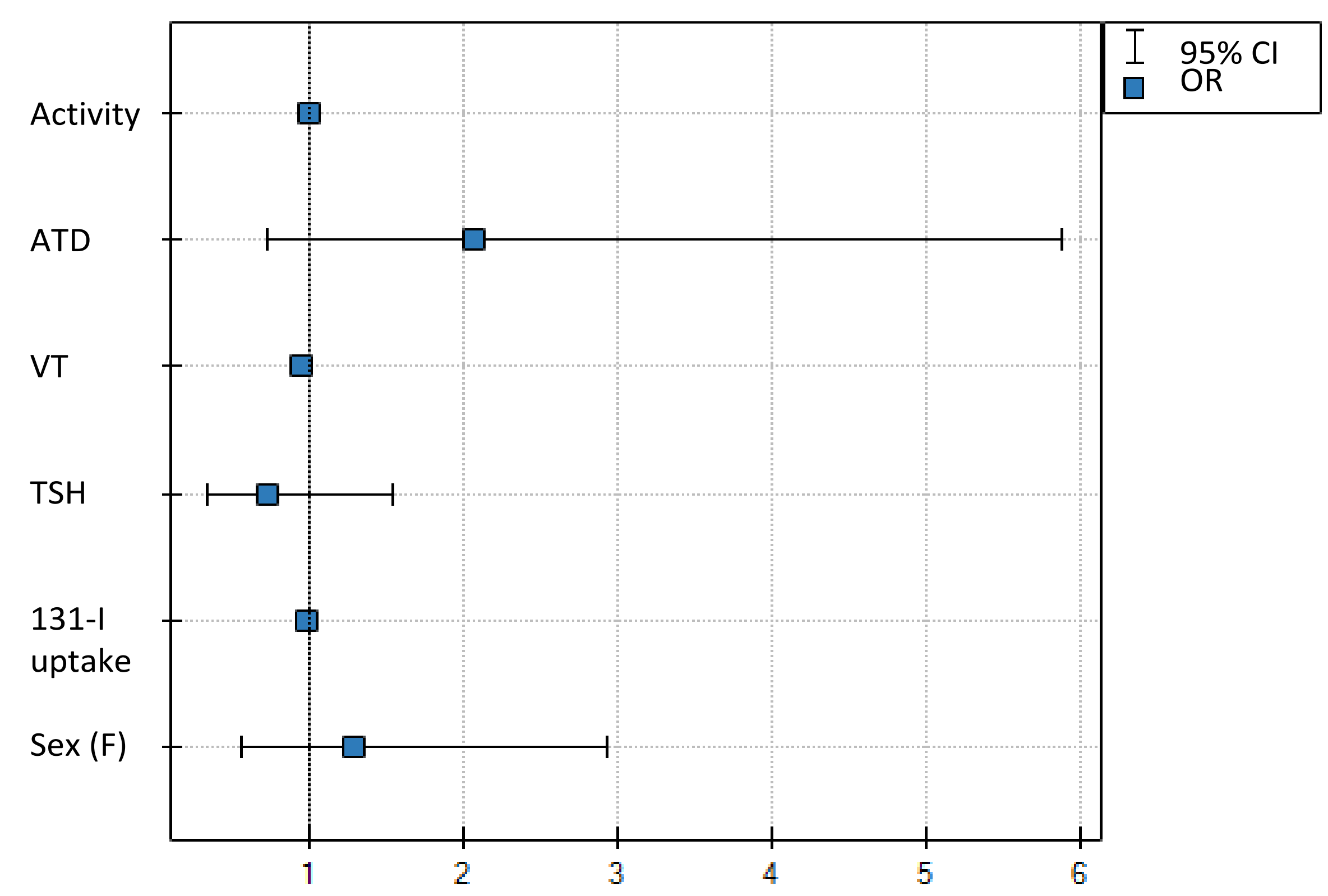

Figure 5. Factors influencing 131-I therapy efficacy in patient group without focal lesions in thyroid as evidenced by US: 6 months after treatment (logistic regression, $\mathrm{N}=198$ $95 \% \mathrm{Cl}=0,923-0,975)$.

Only one factor was effective: thyroid volume - the smaller was the thyroid volume, the more effective was the treatment ( $O R=0.95$, $\mathrm{p}<0.001 ;(95 \% \mathrm{Cl}=0.923-0.975)$.

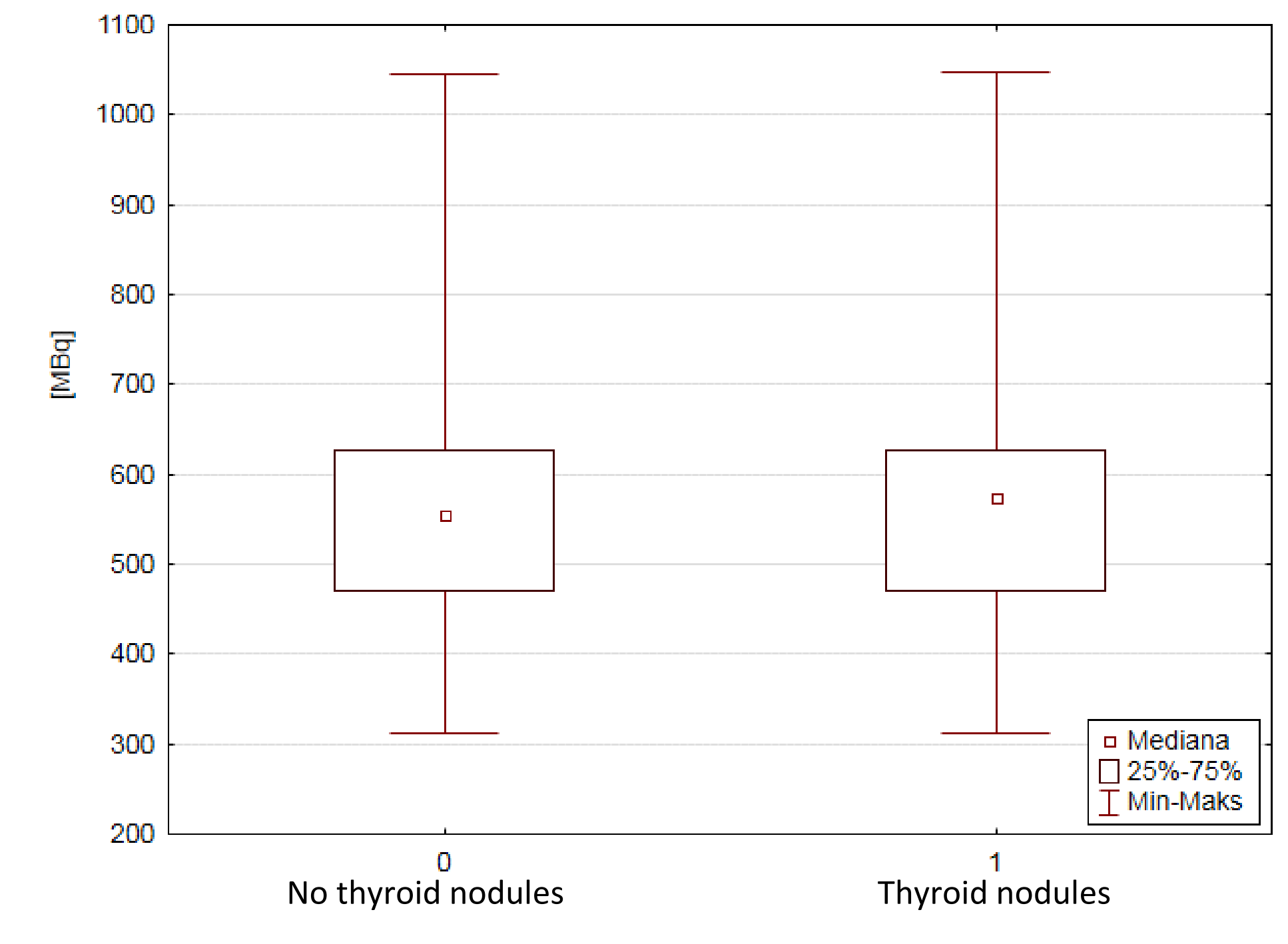

Figure 2. Median values of 131-I activity delivered to patients with or without thyroid nodules ( $U$ Mann-Whitney test, $p=0.0014$ )

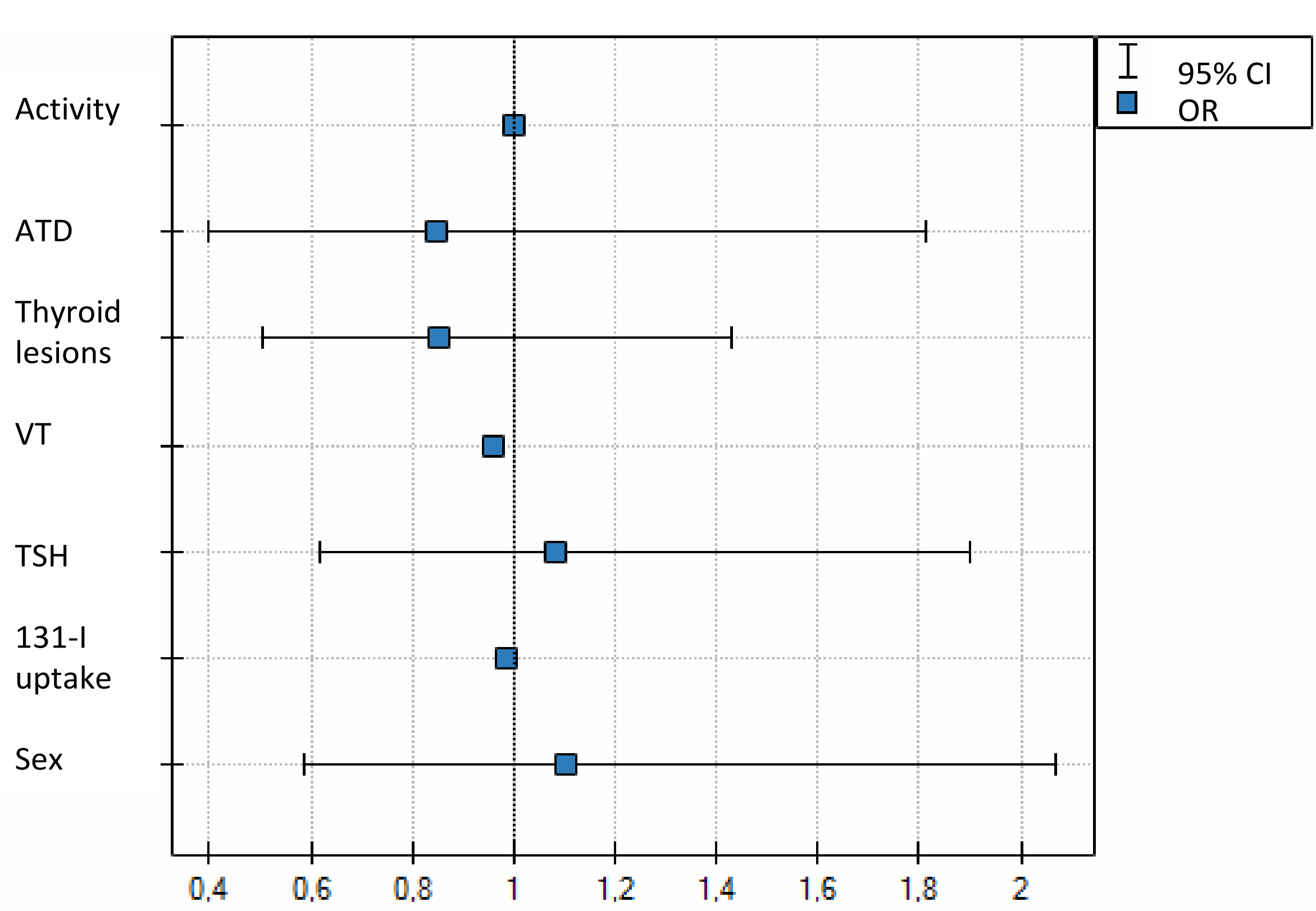

Figure 4. Factors affecting 131-I therapy efficacy - 6 months after treatment (logistic regression, $\mathrm{N}=356$ ).

Only one factor was effective: thyroid volume - the smaller was $0.96, p<0.001 ; 95 \% C(=0.944-0.977)$.

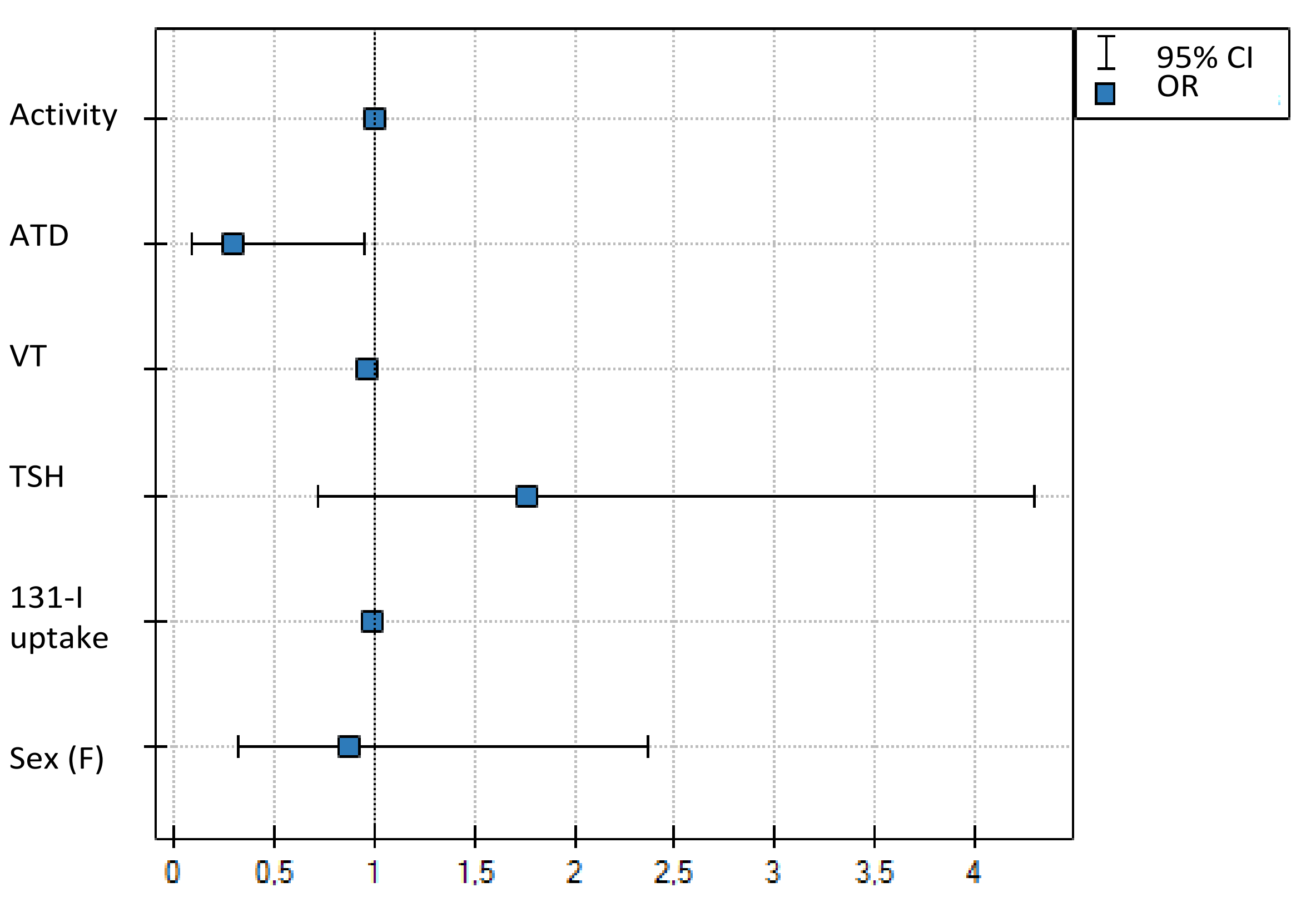

Figure 6. Factors influencing 131-I therapy efficacy in the patient group with focal lesions in thyroid as evidenced by usg 6 months after treatment (logistic regression, $\mathrm{N}=164$ )

Only two factors were effective: thyroid volume - the smaller the volume the more effective was the treatment $(\mathrm{OR}=0.97, \mathrm{p}<0.003$

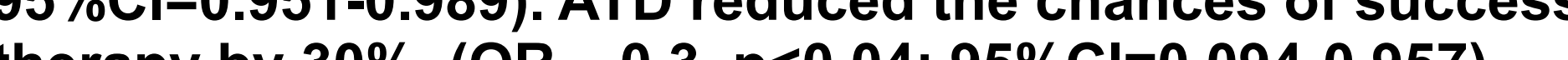

\section{Conclusions:}

The efficacy of 131-I treatment in GD patients with or without focal lesions evaluated after 6 months was negatively affected by larger thyroid volumes.

The efficacy of 131-I treatment in GD patients with focal lesions evaluated after 6 months was negatively affected by anti-thyroid medication. 